\title{
Article \\ A Sustainable Approach for Extracting Non-Extractable Phenolic Compounds from Mangosteen Peel Using Ultrasound-Assisted Extraction and Natural Deep Eutectic Solvents
}

\author{
Merichel Plaza ${ }^{1,2}$ (), Gloria Domínguez-Rodríguez ${ }^{1}$, Cristina Sahelices ${ }^{1}$ and María Luisa Marina ${ }^{1,2, *(1)}$ \\ 1 Facultad de Ciencias, Departamento de Química Analítica e Ingeniería Química, Universidad de Alcalá, Ctra. \\ Madrid-Barcelona Km 33.600, 28871 Alcalá de Henares, Madrid, Spain; merichel.plaza@uah.es (M.P.); \\ gloria.dominguezr@uah.es (G.D.-R.); cristina.sahelices@uah.es (C.S.) \\ 2 Instituto de Investigación Química Andrés M. del Río (IQAR), Universidad de Alcalá, Ctra. \\ Madrid-Barcelona Km 33.600, 28871 Alcalá de Henares, Madrid, Spain \\ * Correspondence: mluisa.marina@uah.es; Tel.: +34-91-885-4935
}

Citation: Plaza, M.;

Domínguez-Rodríguez, G.; Sahelices,

C.; Marina, M.L. A Sustainable

Approach for Extracting

Non-Extractable Phenolic

Compounds from Mangosteen Peel

Using Ultrasound-Assisted

Extraction and Natural Deep Eutectic

Solvents. Appl. Sci. 2021, 11, 5625.

https://doi.org/10.3390/

app11125625

Academic Editors: Miguel

Ángel Rodríguez Delgado and

Bárbara Socas Rodríguez

Received: 24 May 2021

Accepted: 16 June 2021

Published: 18 June 2021

Publisher's Note: MDPI stays neutral with regard to jurisdictional claims in published maps and institutional affiliations.

Copyright: (c) 2021 by the authors. Licensee MDPI, Basel, Switzerland. This article is an open access article distributed under the terms and conditions of the Creative Commons Attribution (CC BY) license (https:// creativecommons.org/licenses/by/ $4.0 /)$.

\begin{abstract}
Mangosteen (Garcinia mangostana L.) peel is a potential source of phenolic compounds with beneficial properties. Natural deep eutectic solvents (NaDES) have been considered an environmentally friendly and cheap alternative to conventional organic solvents. In this work, a green extraction methodology was developed using ultrasound-assisted extraction (UAE) and NaDES for the extraction of antioxidant non-extractable polyphenols (NEPs) from mangosteen peel. To select the best NaDES to extract NEPs from mangosteen peel, seven NaDES were studied. Antioxidant capacity and total phenolic and proanthocyanidin contents were determined for the extracts. The molecular weights for the NEPs present in those extracts were evaluated by size exclusion chromatography. Experimental results showed that choline chloride-lactic acid (1:2) was the NaDES allowing the highest antioxidant proanthocyanidin content in the extracts. A Box-Behnken experimental design was employed to optimize the main parameters in UAE with NaDES: water percentage, ultrasound amplitude, and extraction time. The optimal extraction conditions were $18.8 \%(v / v)$ water, $60 \%$ ultrasound amplitude, and $15 \mathrm{~min}$ as the extraction time. In addition, the cytotoxicity of the NEP extracts obtained under optimal extraction conditions was evaluated. Results indicated for the first time that the use of NaDES in combination with UAE could be a sustainable alternative for the extraction of antioxidant NEPs from mangosteen peel for important applications in the food, pharmaceutical, agrochemical, and cosmetic fields, as the extracts presented low cytotoxicity.
\end{abstract}

Keywords: natural deep eutectic solvent; sustainable extraction; non-extractable polyphenols; mangosteen peel; ultrasound-assisted extraction; response surface methodology

\section{Introduction}

Every year, large amounts of food waste are produced in the agri-food industry worldwide [1]. For instance, fruit processing produces large amounts of by-products, which represent around $25-60 \%$ of fruit weight (mainly peel, and in a lower percentage, pulp and seeds) [2]. These by-products are usually discarded, causing serious environmental problems derived from their incineration or by sending them to landfills. However, fruit peel can be an attractive source of bioactive compounds, and its exploitation might be contemplated as an interesting possibility from the economic and environmental points of view $[2,3]$.

Mangosteen (Garcinia mangostana L.) is one of the best-tasting tropical fruits, mostly found in countries from Southeast Asia such as India, Myanmar, Malaysia, the Philippines, Sri Lanka, and Thailand. Also known as "the queen of fruits" due to the unique sweet-sour taste of the edible pulp, which is mainly consumed fresh as a dessert, its dark red peel is 
discarded and considered a waste [4,5]. The peel from this fruit is a potential source of antioxidant phenolic compounds such as phenolic acids, tannins, xanthones, and anthocyanins [6-8]. Studies about the presence of phenolic compounds in mangosteen peel have only been focused on the extraction of polyphenols through the use of aqueous-organic solvents without paying enough attention to bound polyphenols that remain in the residues after solvent extraction [5,9-11]. These underestimated compounds with interesting biological properties are known as non-extractable polyphenols (NEPs) [12]. NEPs include high-molecular-weight polymeric polyphenols and individual low-molecular-weight phenolic compounds, bound to dietary fiber or other macromolecules through hydrophobic interactions and hydrogen and covalent bonding [13,14]. As far as we know, the presence of NEPs has not been yet studied in mangosteen peels.

In order to carry out the extraction of NEPs from natural sources, acid, alkaline, or enzymatic hydrolysis of the extraction residue is needed to release these compounds from macromolecules. However, many phenolic compounds are sensitive at very high $\mathrm{pH}$ conditions during acid and alkaline hydrolysis, which might change the structure of NEPs, breaking down non-covalent complexes and making it difficult to recognize their original conformations. In addition, these three treatments should be employed carefully because there is a possibility of breaking covalent bonds in the polyphenols [15].

In the last few years, society has increased its interest in the development of green methodologies due to higher awareness about the environment. Therefore, one of the goals of this work was to contribute to a more sustainable extraction process following green chemistry principles, in which the extract was obtained while having the lowest environmental impact (minimizing the employ of organic solvents and energy) [16]. In that sense, novel solvents known as natural deep eutectic solvents (NaDES), which can replace the use of organic solvents in the extraction of bioactive compounds due to their great bio-affinity and little toxicity, have been recognized as sustainable and safe [17,18]. Therefore, these solvents are appropriate for being used in pharmaceutical, cosmetic, agrochemical, and food applications [17]. NaDES are deep eutectic mixtures comprising two or more natural compounds common in living cells and acting as either hydrogen bond donors (HBD) or hydrogen bond acceptors (HBA) such as choline chloride, amino acids, sugars, and organic acids, among others [19]. These solvents have shown great potential for extraction processes because of the strong hydrogen bonds that take place between the solvents' components and the extracted compounds. These interactions enable obtaining high extraction yields and preserve the extract, protecting the bioactive compounds from degradation $[19,20]$. That is why NaDES have been previously employed for the extraction of phenolic compounds from natural sources $[17,19,21]$. In addition, these solvents have enabled the extraction of phenolic compounds in combination with advanced extraction techniques such as ultrasound-assisted extraction (UAE), homogenate (HAE), high hydrostatic pressure (HHPAE), pressurized liquid extraction (PLE), and microwave-assisted extraction (MAE) [22-25]. The main advantages that these extraction techniques present over conventional ones are the reduction of operation time and adverse ecological effects, the decrease in the amount of solvent employed, economizing the operation cost, and maintaining the quality of the compounds of interest. Therefore, they are considered green extraction technologies [17]. For instance, UAE has been widely used for the extraction of phytochemicals as well as for the treatment of biomass [26]. Furthermore, this technique has been applied, along with NaDES, to extract phenolic compounds [27]. Nevertheless, the combination of UAE with NaDES has not been yet studied for extracting NEPs.

This work proposes, for the first time, the development of a sustainable, analytical methodology for the recovery of antioxidant NEPs from Garcinia mangostana L. peels based on the combination of NaDES with UAE technology. Figure 1 shows the procedure carried out in this work for NEP extraction. Different NaDES derived from choline chloride were studied to select the most suitable solvent to extract NEPs from this matrix as well as the best molar ratio between NaDES components. A Box-Behnken design was used to establish the optimal extraction conditions (percentage of water, ultrasound amplitude, and 
extraction time) to attain extracts with high antioxidant capacity and high proanthocyanidin content. Furthermore, the presence of extractable polyphenols (EPPs) recovered through the conventional extraction method from mangosteen peel was compared with the extraction of NEPs performed by UAE with NaDES, using the optimal conditions. The phenolic profile and the molecular weight of the phenolic compounds extracted were determined by reverse-phase HPLC-DAD and size exclusion (SEC)-HPLC, respectively. Finally, the cytotoxicity of the NEP extracts obtained under optimal extraction conditions was studied.

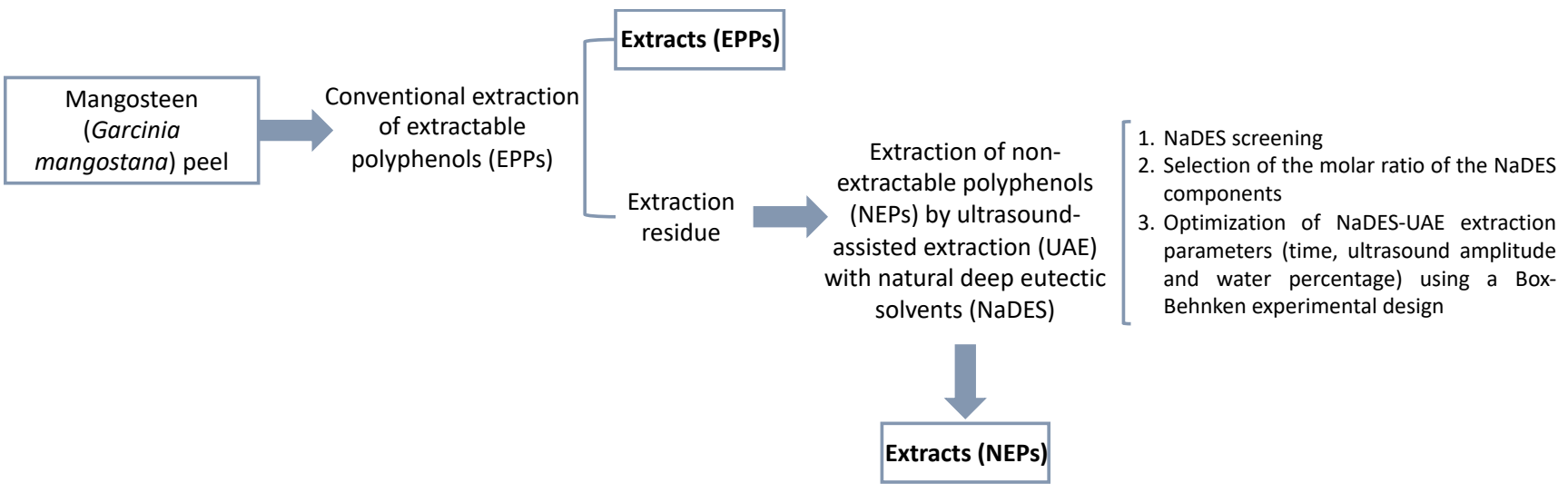

Figure 1. The extraction procedure carried out in this work.

\section{Materials and Methods}

\subsection{Chemicals and Samples}

All reagents were of analytical grade, and ultrapure water $(18.2 \mathrm{M} \Omega / \mathrm{cm})$ was generated with a Millipore system (Millipore, Billerica, MA, USA). Hydrochloric acid (37\%), acetonitrile (99.9\%), acetone, formic acid (98-100\%), and ethanol of HPLC grade as well as trichloroacetic acid (TCA) and urea were obtained from Scharlab Chemie (Barcelona, Spain). Methanol (99.99\%) and butanol of HPLC grade were from Fisher Scientific (Leicestershire, UK). Polyethylene glycol (8000 Da), polyethylene glycol (4000 Da), twin20 (1228 Da), ethylene glycol (62 Da), dextran (50,000 Da), gallic acid, epicatechin, $\alpha$-mangostin, procyanidin $\mathrm{B}_{2}$, vanillin, iron (III) chloride, iron (II) chloride, sodium carbonate, hydrogen peroxide, 6-hydroxy-2,5,7,8-tetramethylchromane-2-carboxylic acid (Trolox), potassium ferricyanide, 4-dimethylaminocinnamaldehyde (DMAC), potassium persulfate, 2,2'-azinobis(3ethylbenzothiazoline-6-sulphonic acid) diammonium salt (ABTS), ferrous sulfate, glycerol, 1,10-phenanthroline, citric acid, D-sorbitol, choline chloride, lactic acid, ethylene glycol, and formic acid were from Sigma-Aldrich (Saint Louis, MO, USA). Sodium dihydrogen phosphate dihydrate and dipotassium hydrogen phosphate were from Merck (Darmstadt, Germany).

Mangosteen fruits (Garcinia mangostana L.) were acquired in a local market (Alcalá de Henares, Madrid, Spain). The fruit pieces were washed, and the peel was separated from its edible pulp and its mesocarp. Next, the peels were ground in a commercial blender and stored at $-20^{\circ} \mathrm{C}$ until their analysis.

\subsection{Preparation of Natural Deep Eutectic Solvents (NaDES)}

Different NaDES were prepared according to Hernández-Corroto et al. [28]. The HBA and HBD components of NaDES are explained in Table 1, along with the molar ratio selected according to the optimal conditions found in the literature for the extraction of phenolic compounds from natural sources. Mixtures were heated in a water bath at $80{ }^{\circ} \mathrm{C}$ with shaking until a clear liquid was attained. 
Table 1. Hydrogen bond acceptors (HBAs) and hydrogen bond donors (HBDs) employed in the synthesis of natural deep eutectic solvents (NaDES).

\begin{tabular}{ccccc}
\hline Component 1 (HBA) & Component 2 (HBD) & Abbreviation & Molar Ratio & Reference \\
\hline Choline chloride & Glycerol & ChCl-gly & $1: 2$ & {$[29]$} \\
Choline chloride & Ethylene glycol & ChCl-EG & $1: 2$ & {$[30]$} \\
Choline chloride & Urea & ChCl-urea & $1: 2$ & {$[31]$} \\
Choline chloride & Sorbitol & ChCl-sorb & $1: 1$ & {$[32]$} \\
Choline chloride & Lactic acid & ChCl-LA & $1: 2$ & {$[33]$} \\
Choline chloride & Citric acid & ChCl-CA & $2: 1$ & {$[34]$} \\
Choline chloride & Formic acid & ChCl-FA & $1: 2$ & {$[33]$} \\
\hline
\end{tabular}

\subsection{Extraction of Extractable Polyphenols (EPPs)}

The EPP extraction was performed using the conventional solid-liquid extraction method described by Condezo-Hoyos et al. [35], Zurita et al. [36], and Taha et al. [37]. The mixture composed of $15.0 \mathrm{~g}$ mangosteen peel sample and $20 \mathrm{~mL}$ methanol/water (50:50, $v / v, \mathrm{pH} 2.0)$ acidified with $2 \mathrm{~N} \mathrm{HCl}$ was agitated for $1 \mathrm{~h}$ at room temperature. To collect the supernatant, the obtained extract was centrifuged at $4000 \times g$ for $10 \mathrm{~min}$. Next, the extraction residue was submitted again to extraction by adding $20 \mathrm{~mL}$ of acetone/water $(70: 30, v / v)$ and shaking for $1 \mathrm{~h}$ at room temperature as well as centrifugation at $4000 \times g$ for $10 \mathrm{~min}$. The supernatants collected in both extractions, methanol and acetone, were mixed at the end. The extractions were achieved in triplicate, and the extraction residue was then dried in a centrifugal concentrator (Eppendorf AG, Hamburg, Germany) for $1 \mathrm{~h}$ and $30 \mathrm{~min}$. Thereafter, the extraction residue was ready to be employed in the NEPs' extraction.

\subsection{Extraction of Non-Extractable Polyphenols (NEPs)}

To obtain NEPs, an ultrasound-assisted extraction technique (UAE) was employed along with the different NaDES grouped in Table 1. Briefly, $50 \mathrm{mg}$ of the extraction residue, recovered after the conventional extraction of EPPs of mangosteen peel, was mixed with $1 \mathrm{~mL}$ of NaDES:water $(70: 30 ; v / v)$. The mixture was sonicated with an ultrasound probe (model VCX130, Sonics Vibra-Cell, Hartford, CT, USA) for $1 \mathrm{~min}$ at $30 \%$ amplitude [28]. The extracts obtained were subsequently centrifuged for $15 \mathrm{~min}$ at $10^{\circ} \mathrm{C}$ and $12,000 \times \mathrm{g}$. The supernatant obtained was saved and used for the following analysis. All the extractions were performed in triplicate. After the selection of NaDES and the molar ratio between NaDES components (1:1, 1:2, and 1:3), a second-order Box-Behnken design based on three levels and three central points was employed to optimize conditions using Statgraphics Centurion XVII software (Statpoint Technologies, Inc., Warrenton, VA, USA). The effects of the percentage of water $(10,20$, and $30 \%, v / v)$, ultrasound amplitude $(30,45$, and $60 \%)$, and extraction time $(1,8$, and $15 \mathrm{~min})$ were investigated. In total, 15 experiments were achieved in a random run order (Table S1). The total proanthocyanidin content (DMAC and butanol $/ \mathrm{HCl}$ assays) and total antioxidant capacities (capacity to inhibit the formation of hydroxyl radical, capacity to scavenge free radicals, and ferric-reducing antioxidant power (FRAP)) were the response variables $\left(Y_{i}\right)$. Experimental data were fitted with the second-order polynomial equation:

$$
\begin{gathered}
Y_{i}=\beta_{0}+\beta_{1} W+\beta_{2} A+\beta_{3} T+\beta_{1,2} W \times A+\beta_{1,3} W \times T+\beta_{2,3} A \times T \\
+\beta_{1,2,3} W \times A \times T+\text { error }
\end{gathered}
$$

where $W$ was the water percentage in the solvent; $A$ was the ultrasound amplitude; $T$ was the extraction time; $\beta_{0}$ was the linear regression coefficient; $\beta_{1}, \beta_{2}$, and $\beta_{3}$ were the linear effects; $\beta_{1,2}, \beta_{1,3}$, and $\beta_{2,3}$ were the two-factor interaction effects; $\beta_{1,2,3}$ was the three-factor interaction effect; and error was the error variable. To evaluate the adequacy of the fitted model settled between water percentage, ultrasound amplitude, and extraction time, and the different responses, analysis of variance (ANOVA) was employed. A combination of experimental factors looking to maximize the desirability function was used to calculate a 
multiple response optimization. The experimental extractions under the theoretical optimal extraction conditions using UAE with NaDEs were performed in triplicate to verify the experimental design.

\subsection{Total Proanthocyanidin Content}

\subsubsection{DMAC Assay}

The DMAC assay described by Montero et al. [38], with some modifications, was employed to measure total proanthocyanidin (PA) content. For this purpose, a DMAC solution $(0.1 \%$ DMAC reagent $(w / v)$ in a mixture of ethanol/water/ $\mathrm{HCl} 75: 12.5: 12.5, v / v / v)$ was prepared just before its use. Next, $140 \mu \mathrm{L}$ of the extract was mixed with $420 \mu \mathrm{L}$ of the DMAC solution. The mixture was kept at room temperature for $15 \mathrm{~min}$ to favor the reaction. Later, the absorbance was measured at $640 \mathrm{~nm}$. Additionally, NaDES $(140 \mu \mathrm{L})$ were used as blanks instead of the sample. A calibration curve using epicatechin $(0.001-0.020 \mathrm{mg} / \mathrm{mL})$ was employed to estimate the concentration of total proanthocyanidin. The results were indicated as $\mathrm{mg}$ of epicatechin/100 $\mathrm{g}$ sample.

\subsubsection{Butanol/HCl Assay}

Butanol/ $\mathrm{HCl}$ assay was carried out according to Pérez-Jiménez et al. [39] with some adjustments. In brief, $50 \mu \mathrm{L}$ of the extract was mixed with $200 \mu \mathrm{L}$ of butanol/ $\mathrm{HCl}(95: 5$ $v / v$ ) with $0.7 \mathrm{~g}$ of $\mathrm{FeCl}_{3}$ at $100{ }^{\circ} \mathrm{C}$ for $60 \mathrm{~min}$. After this time, to collect the supernatant, the samples were subjected to centrifugation $(10,000 \mathrm{rpm})$ for $10 \mathrm{~min}$. After $0.125 \mathrm{~mL}$ of butanol was added twice, supernatants were combined, and absorbance was measured at $555 \mathrm{~nm}$. The PA content was indicated as $\mathrm{mg}$ epicatechin/100 g sample, which was obtained through a standard curve $(0.025-2.000 \mathrm{mg} / \mathrm{mL})$.

\subsection{Antioxidant Capacity Determination}

\subsubsection{ABTS Radical Assay}

ABTS radical scavenging activity assay was achieved according to Re et al. [40], with some modifications [41]. The oxidation of ABTS with potassium persulfate was needed to generate the ABTS radical, forming a deep green solution. ABTS $(7 \mathrm{mM})$ and potassium persulfate $(2.45 \mathrm{mM})$ were combined and left in the dark for at least $16 \mathrm{~h}$ to obtain the ABTS stock solution. Fresh daily ABTS ${ }^{\bullet+}$ working solution, with an absorbance around 0.7 at $734 \mathrm{~nm}$, was made by mixing ABTS $^{\bullet+}$ stock solution and $5 \mathrm{mM}$ phosphate buffer $(\mathrm{pH}$ 7.4). Next, $10 \mu \mathrm{L}$ of extract ( $50 \mathrm{mg}$ sample $/ \mathrm{mL}$ ) was mixed with $990 \mu \mathrm{L}$ of fresh ABTS ${ }^{\bullet+}$ working solution. Finally, the reaction mixture was kept in the dark for $45 \mathrm{~min}$ at room temperature, and absorbance was determined at $734 \mathrm{~nm}$. ABTS radical scavenging capacity was determined by the following equation:

$$
\text { ABTS radical scavenging capacity }(\%)=\left(\frac{\text { Abs blank }- \text { Abs sample }}{\text { Abs blank }}\right) \times 100
$$

where Abs blank was the absorbance of $10 \mu \mathrm{L}$ of the NaDES with $990 \mu \mathrm{L} \mathrm{ABTS}{ }^{\bullet+}$ working solution, and Abs sample was the absorbance of $10 \mu \mathrm{L}$ of the extract with $990 \mu \mathrm{L}$ ABTS ${ }^{\bullet+}$ working solution.

\subsubsection{Capacity to Inhibit the Formation of a Hydroxyl Radical Assay}

The capacity to inhibit the formation of hydroxyl radicals was evaluated, following the method described by Ajibola et al. [42] with some modifications [41]. Hydroxyl radicals are obtained through the Fenton reaction because of the oxidation of Fe (II) to $\mathrm{Fe}$ (III) by $\mathrm{H}_{2} \mathrm{O}_{2}$. Phenolic compounds will inhibit the formation of hydroxyl radicals by preventing this oxidation reaction. To achieve this, $50 \mu \mathrm{L}$ of $3 \mathrm{mM}$ 1,10-phenanthroline in $0.1 \mathrm{M}$ phosphate buffer (pH 7.4) was combined with $50 \mu \mathrm{L}$ of $3 \mathrm{mM}$ ferrous sulfate, $50 \mu \mathrm{L}$ of peel extract (extract concentrations: $50 \mathrm{mg}$ sample/mL for the assays made during the selection of $\mathrm{NaDES}$ and the molar relation of NaDES components and $5 \mathrm{mg}$ sample/mL for the assays carried out during extraction optimization and conventional extraction), and $50 \mu \mathrm{L}$ of 
$0.01 \% \mathrm{H}_{2} \mathrm{O}_{2}$. To start the reaction, the mixture was incubated for $1 \mathrm{~h}$ at $37^{\circ} \mathrm{C}$ and $700 \mathrm{rpm}$. Next the absorbance corresponding to the complex Fe(II)-phenanthroline was measured at $536 \mathrm{~nm}$. The results were expressed as \% of hydroxyl radical formation inhibition using the following equation:

$$
\%=\left(\frac{\text { Abs sample }- \text { Abs blank }}{\text { Abs control }- \text { Abs blank }}\right) \times 100
$$

where Abs sample was the absorbance of the sample extracts, Abs blank was the absorbance of the NaDES, and Abs control was the absorbance of a control solution prepared by adding water instead of $\mathrm{H}_{2} \mathrm{O}_{2}$ and $\mathrm{NaDES}$.

\subsubsection{Ferric-Reducing Antioxidant Power (FRAP)}

The FRAP method implemented by Ajibola et al. [42], with some modifications, was applied. Briefly, $25 \mu \mathrm{L}$ of the extract, $25 \mu \mathrm{L}$ of $0.2 \mathrm{M}$ phosphate buffer $(\mathrm{pH} 6.6)$, and $50 \mu \mathrm{L}$ of $1 \%(w / v)$ potassium ferricyanide were mixed. Next, this mixture was kept at $50{ }^{\circ} \mathrm{C}$ for $20 \mathrm{~min}$ in agitation $(700 \mathrm{rpm})$. The reaction was stopped by adding $50 \mu \mathrm{L}$ of $10 \%(w / v)$ of TCA. Finally, $100 \mu \mathrm{L}$ of the above solution was mixed with $600 \mu \mathrm{L}$ of $0.08 \%$ $(w / v) \mathrm{FeCl}_{3}$ and stood for $3 \mathrm{~min}$. After that, the absorbance was measured at $700 \mathrm{~nm}$ in a microplate spectrophotometer reader (Multiskan Sky, ThermoFisher, Germering, Germany) and compared to the glutathione (GSH) calibration curve $(0.125-0.870 \mathrm{mg} / \mathrm{mL})$ prepared equally. GSH is a tripeptide that reacts directly with free radicals and pro-oxidants, reducing their levels in a cell to a safe minimum [43]. The total antioxidant capacity was expressed as mg GSH/g sample.

\subsection{Determination of NEPs' Molecular Weight from Mangosteen Peel Extracts by High-Performance Liquid Size-Exclusion Chromatography (HPLC-SEC)}

Estimation of the molecular weight range of NEPs extracted under the optimal extraction conditions from mangosteen peel extracts was carried out by SEC using an HPLC system 1100 series from Agilent (Agilent Technologies, Palo Alto, CA, USA) according to Domínguez-Rodríguez et al. [44]. The HPLC instrument had an online degasser, a quaternary solvent pump, an auto-sampler, a column heater compartment, and a diode array detector (DAD) with scanning capabilities. The instrument was controlled by ChemStation (Agilent) software. Separation was performed on a size-exclusion chromatography (SEC) column (PolySep-GFC-P2000, $300 \times 7.8 \mathrm{~mm}$, Phenomenex, Torrance, CA, USA) with a fractionation range of $100 \mathrm{Da}-10 \mathrm{KDa}$., using 100\% water as the mobile phase. Elution was performed in isocratic mode at $0.3 \mathrm{~mL} / \mathrm{min}$ for $60 \mathrm{~min}$, and the column temperature was $25{ }^{\circ} \mathrm{C}$. Twenty microliters of extract were injected. The detection wavelength employed was $280 \mathrm{~nm}$. Different standards were used to calibrate the molecular weight of the SEC column: polyethylene glycol (8000 Da), polyethylene glycol (4000 Da), twin 20 (1228 Da), and ethylene glycol (62 Da). The void volume was determined with dextran (50,000 Da). The molecular weight of the extracted NEPs was determined using the calibration curve obtained with the four standards by plotting the logarithm of the molecular weight as a function of retention time ( $\mathrm{min}$ ). Responses obtained were expressed by a linear equation $(y=-0.085 \times+5.164)$ with an $R^{2}$ determination coefficient value of 0.98572 .

\subsection{Analysis of Phenolic Compounds by HPLC-DAD}

The phenolic profile of the NEP extracts obtained under the optimal extraction conditions was analyzed with the 1100 HPLC-DAD system from Agilent (Agilent Technologies) described in Section 2.7 according to the previously published method with some modifications [45]. Separations were performed with a porous-shell fused-core Ascentis Express C18 analytical column $(150 \mathrm{~mm} \times 2.1 \mathrm{~mm}, 2.7 \mu \mathrm{m})$ with an Ascentis Express C18 guard column $(0.5 \mathrm{~cm} \times 2.1 \mathrm{~mm}, 2.7 \mu \mathrm{m})$, both from Supelco (Bellefonte, PA, USA). The mobile phases consisted of both (A) water with $0.5 \%$ formic acid and (B) acetonitrile with $0.5 \%$ formic acid in a gradient elution analysis, programmed as follows: $0 \mathrm{~min}, 5 \%$ (B); 0-15 $\mathrm{min}$, 
$20 \%$ (B); $15-25 \mathrm{~min}, 30 \%$ (B); and $25-50 \mathrm{~min}, 80 \%$ (B) with $15 \mathrm{~min}$ of post-time for column conditioning at a flow rate of $0.3 \mathrm{~mL} / \mathrm{min}$. The column temperature was set at $50{ }^{\circ} \mathrm{C}$, and the injection volume was $5 \mu \mathrm{L}$ of the extract. The detection wavelengths employed were $210,254,260,280,320,360$, and $510 \mathrm{~nm}$.

\subsection{Cell Viability}

The human cervical cancer HeLa cells from the American Type Culture Collection ATCC (Rockwell, MD, USA) were employed to study cell viability. The cells were maintained under $37{ }^{\circ} \mathrm{C}, 95 \%$ humidity, and $5 \% \mathrm{CO}_{2}$ in culture medium composed of Dulbecco's modified Eagle's medium (DMEM) supplemented with penicillin $(100 \mathrm{U} / \mathrm{mL})$, amphotericin $(250 \mathrm{ng} / \mathrm{mL})$, streptomycin $(10 \mu \mathrm{g} / \mathrm{mL})$, and $10 \%$ fetal bovine serum.

The MTT (3-(4,5-dimethylthiazol-2-yl)-2,5-diphenyltetrazolium bromide) assay described by Hernández-Corroto et al. [41], with some modifications, was used to measure the impact of different concentrations of NEP extract on cell viability. First, HeLa cells were seeded in 96-well plates (10,000 cells/well), and they were incubated for $24 \mathrm{~h}$. After, the cell medium was interchanged using DMEM together with different concentrations of NEP extract $(0.025-0.500 \mathrm{mg} / \mathrm{mL})$ diluted in water, employing a total volume of $200 \mu \mathrm{L} /$ well and using DMEM medium without samples as a control. In addition, milli-Q water was added to the NaDES in the same amount as the extract dilutions to determine the solvent cytotoxicity. Afterward, $10 \mu \mathrm{L}$ of $5 \mathrm{mg} / \mathrm{mL}$ MTT stock solution in phosphate buffer was added to each well and incubated for $3 \mathrm{~h}$. Next, the medium was detached, and $200 \mu \mathrm{L}$ of dimethyl sulfoxide was added to dissolve formazan crystals.

The absorbance of formazan solutions was determined at $570 \mathrm{~nm}$ (with a reference wavelength of $630 \mathrm{~nm}$ ). Percentage of cell viability was determined as follows:

$$
\% \text { cell viability }=\frac{\text { Abs sample }}{\text { Abs control }} \times 100
$$

\subsection{Statistical Analysis}

Statistical analysis was carried out employing Statgraphics Centurion version XVII software (Statistical Graphics Corp, USA) to compare the total PA content and antioxidant capacity of the extracts obtained by UAE with the different NaDES. Values were expressed as mean \pm standard deviation. To determine statistically significant differences $(p \leq 0.05)$ between mean values for different extracts at a 95\% confidence level, an analysis of variance (ANOVA) with Fisher's exact test was utilized. All the analyses were performed in triplicate for each extract.

\section{Results and Discussion}

\subsection{NaDES Screening for the Extraction of NEPs from Mangosteen Peel}

After the conventional extraction of EPPs from mangosteen peel, the recovery of NEPs from the extraction residue was studied by employing seven different NaDES in combination with UAE (see Table 1 and Figure 1). These NaDES were selected according to different studies found in the literature about the extraction of phenolic compounds from natural sources $[30,32,46]$. The selection of NaDES was of great importance, considering their properties such as viscosity, polarity, physicochemical interactions, and solubility [30]. For instance, the relatively high viscosity of NaDES at room temperature may decrease the mass transfer rates from the matrix to the solvent. Thus, in the solvent screening, $30 \%(v / v)$ water content was set to reduce solvent viscosities. In addition, UAE was the extraction technique employed because it was based on a phenomenon called cavitation. The ultrasonic waves generated by the ultrasound probe were compressed and stretched, providing small gas bubbles to the liquid medium. These bubbles increased their volumes, achieving a critical size in which the gas phase could not be kept in the bubble because the ultrasound energy was not enough, and then the bubbles imploded, discharging a lot of energy. Therefore, bubble cavitation allowed the separation of the bonds among molecules generating radicals and thus increased the extraction of the compounds [47]. The UAE 
conditions employed to select the best NaDES to release NEPs from the extraction residue of mangosteen peel are described in Section 2.4. Total PA content and antioxidant capacity of the extracts obtained with the seven different NaDES based on choline chloride and acids (lactic, citric, and formic acids), polyalcohols (ethylene glycol, sorbitol, and glycerol), and a nitrogen-containing substance (urea) were studied, and the results are shown in Table 2. NaDES composed of choline chloride-sugars were not employed because several studies reported the poor extraction efficiency of these NaDES for the recovery of phenolic compounds from natural matrices [48-50].

Table 2. Total PA content (DMAC and butanol/ $\mathrm{HCl}$ assays) and total antioxidant capacity (ABTS radical scavenging activity and capacity to inhibit the formation of hydroxyl radical assays), obtained from the extraction residue of mangosteen peel by UAE with different NaDES.

\begin{tabular}{|c|c|c|c|c|}
\hline NaDES & $\begin{array}{c}\text { DMAC } \\
\text { (mg Epicatechin/100 g Sample) }\end{array}$ & $\begin{array}{c}\text { Butanol/HCl } \\
\text { (mg Epicatechin/100 g Sample) }\end{array}$ & $\begin{array}{l}\text { Hydroxyl Radical } \\
\text { (\% of Inhibition) }\end{array}$ & $\begin{array}{c}\text { \% Scavenging of } \\
\text { ABTS Radicals }\end{array}$ \\
\hline ChCl:FA & $18 \pm 1^{b}$ & $1767 \pm 197^{b, c}$ & $71 \pm 17^{a}$ & $41 \pm 2^{d}$ \\
\hline ChCl:LA & $25.4 \pm 0.6^{\mathrm{a}}$ & $2447 \pm 237^{\mathrm{a}}$ & $24 \pm 5^{\mathrm{d}}$ & $34 \pm 2^{\mathrm{e}}$ \\
\hline ChCl:sorb & $5 \pm 1^{f}$ & $759 \pm 52^{d}$ & $58 \pm 10^{b}$ & $49 \pm 5^{c}$ \\
\hline ChCl:EG & $9.2 \pm 0.9^{\mathrm{e}}$ & $623 \pm 110^{e}$ & $39 \pm 8^{c}$ & $65 \pm 4^{a}$ \\
\hline $\mathrm{ChCl}: \mathrm{CA}$ & $15 \pm 2^{d}$ & $1493 \pm 72^{c}$ & & $25 \pm 2 \mathrm{~g}$ \\
\hline ChCl:urea & & $415 \pm 57^{\mathrm{e}}$ & $9 \pm 4^{\mathrm{e}}$ & $61 \pm 2^{b}$ \\
\hline ChCl:gly & $16.5 \pm 0.5^{c}$ & $1954 \pm 184^{b}$ & $10 \pm 4^{\mathrm{e}}$ & $30 \pm 6^{f}$ \\
\hline
\end{tabular}

Note: ${ }^{a, b, c, d, e, f, g}$ Different superscript letters indicate the significant differences $(p \leq 0.05)$.

The total PA content that remained in the extraction residue of mangosteen peel was established using two spectrophotometric methods, DMAC and butanol/ $\mathrm{HCl}$. At present, for the quantification of PAs, the DMAC assay is favored over others such as the vanillin assay. Despite having similarities, DMAC is considered to have higher sensitivity and in addition, light absorbance is measured at $640 \mathrm{~nm}$ in the DMAC assay, reducing the possibility of interference from anthocyanins and being more specific to determine monomers [51]. On the other hand, the butanol $/ \mathrm{HCl}$ assay involves depolymerization of the polymer in acid and conversion of the monomers to anthocyanidin, being more specific when determining polymers than the DMAC assay, which can be spectrophotometrically quantified [52]. According to Table 2, similar results were obtained using both assays, DMAC and butanol/ $\mathrm{HCl}$, the extracts achieved with $\mathrm{ChCl}$ :LA being the ones with the highest PA content using the DMAC and butanol/ $\mathrm{HCl}$ assays $(25.4$ and $2447 \mathrm{mg}$ epicatechin/100 g of sample, respectively). In the DMAC assay, the extracts that also showed high PA content were those collected with $\mathrm{ChCl}$ :FA, followed by $\mathrm{ChCl}$ :gly and $\mathrm{ChCl:CA}$ (15-18 mg epicatechin/100 g of sample). Nevertheless, the butanol/HCl assay also showed that these NaDES allowed the release of a high total PA content to the extracts with no significant differences $(p \geq 0.05)$ between the ChCl:FA extract (1767 mg epicatechin/100 g of sample) and the ChCl:Gly and ChCl:CA extracts (1954 and $1493 \mathrm{mg}$ epicatechin/100 $\mathrm{g}$ of sample, respectively) (Table 2). In both assays, the extracts with the lowest PA values were obtained with the NaDES ChCl:EG, $\mathrm{ChCl}$ :sorb, and ChCl:urea. With ChCl:urea, no results could be obtained for the total PA content with DMAC assay because DMAC reacts with urea, this being a method that is also used to detect the presence of urine in samples [53]. Therefore, more-polar NaDES composed of organic acids such as lactic acid, formic acid, and citric acid extracted greater amounts of PAs than less-polar NaDES based on sugar and polyalcohol such as the NaDES composed of sorbitol [54]. In addition, organic acid-based NaDES were more acidic $(\mathrm{pH}<3)$, and this medium favored the extraction of anthocyanins and other phenolic compounds as well as their stability [23]. These results suggested that many PAs remained retained on the extraction residue of mangosteen peels after the conventional extraction of EPPs.

On the other hand, to evaluate the antioxidant capacity of extracts, ABTS and hydroxyl radical scavenging assays were employed. The advantage of using two different methods 
was that they could provide wider knowledge of the chemical composition of the extracts as well as their capacities against different radicals. The first assay measured the inhibition capacity of the $\mathrm{ABTS}^{\bullet+}$ radical and was based on the electron transfer reaction, while the second assay evaluated the capacity to inhibit the formation of hydroxyl radicals and was based on the transfer of hydrogen atoms. Table 2 shows the results attained with these two methods for the extracts obtained from the residue of mangosteen peels by UAE with different NaDES. According to the ABTS assay, all extracts obtained by UAE with different NaDES presented significant differences in their antioxidant capacities $(p \leq 0.05)$. The $\mathrm{ChCl}$ :EG extracts exhibited the highest antioxidant capacity (65\% ABTS radical scavenging), followed by those corresponding to $\mathrm{ChCl}$ :urea (61\% ABTS radical scavenging), $\mathrm{ChCl}$ :sorb (49\% ABTS radical scavenging), and ChCl:FA (41\% ABTS radical scavenging). However, the $\mathrm{ChCl}: \mathrm{LA}, \mathrm{ChCl}: \mathrm{gly}$, and $\mathrm{ChCl}: \mathrm{CA}$ extracts showed the lowest capacity to scavenge ABTS radicals (34, 30, and $25 \%$, respectively) (Table 2 ).

As can be observed in Table 2, the capacity to inhibit the formation of hydroxyl radicals of NEPs extracts from mangosteen peel ranged from 9 to $71 \%$. For instance, the $\mathrm{ChCl}$ :FA extracts were the most active, showing an inhibition of hydroxyl radical formation of $71 \%$, followed by $\mathrm{ChCl}$ :sorb with $58 \%$ and $\mathrm{ChCl}$ :EG with $39 \%$. In addition, the extracts obtained with ChCl:LA, ChCl:gly, and ChCl:urea exhibited the lowest inhibition of the formation of hydroxyl radicals (9-24\%). No significant differences were observed between the extracts of ChCl:gly and $\mathrm{ChCl}$ :urea $(p>0.05)$. However, the extract obtained with $\mathrm{ChCl}: \mathrm{CA}$ did not show antioxidant capacity with this assay.

The differences among the results achieved by the two different assays employed might have been due to the different types of antioxidant NEPs recovered that could be more active with a specific type of radical (Table 2). Each radical presented a different mechanism of action $[55,56]$. In general, the results showed that the three most active extracts were those obtained by $\mathrm{ChCl}: \mathrm{EG}, \mathrm{ChCl}$ :sorb, and ChCl:FA solvents, while the extract with the lowest antioxidant capacity corresponded to the one obtained with the $\mathrm{NaDES} \mathrm{ChCl:CA}$.

Taking into account the results shown in Table 2, two NaDES, ChCl:EG and ChCl:LA, were selected to carry out the optimization of the molar ratio of their components. These two NaDES were chosen based on the fact that $\mathrm{ChCl}$ :EG showed high antioxidant capacity with both assays employed, while ChCl:LA presented the highest total PA content using both methods (DMAC and butanol/HCl).

\subsection{Selection of the Molar Ratio of the NaDES Components}

A study on the effects of the molar ratios of the components acting as HBAs and HBDs of $\mathrm{ChCl}: \mathrm{EG}$ and $\mathrm{ChCl}: \mathrm{LA}$ on NEP extraction from mangosteen peel using UAE was carried out. Three different ratios were employed: 1:1, 1:2, and 1:3 (HBA:HBD) for the synthesis of NaDES. However, ChCl:EG (1:1) solvent could not be synthesized because at the 1:1 (HBA:HBD) molar ratio, it crystallized once it was cooled. Table 3 shows the results of total antioxidant capacity (ABTS and hydroxyl radical assays) as well as total PA content (DMAC and butanol/HCl methods) for the extracts obtained by UAE from the extraction residue of mangosteen peel using these two NaDES at different molar ratios. Regarding $\mathrm{ChCl}$ :LA, the extracts obtained with a 1:2 molar ratio presented the highest antioxidant capacity concerning the scavenging of ABTS radicals. However, the capacity to inhibit the formation of hydroxyl radicals was similar among molar ratios (no statistical differences were observed $(p>0.05))$. On the other hand, with respect to ChCl:EG, the extracts attained with the 1:2 molar ratio presented greater antioxidant capacity (65\% scavenging of ABTS radicals and $39 \%$ inhibition of hydroxyl radical formation) than the extracts corresponding to a 1:3 molar ratio. Nevertheless, the extracts presenting the highest PA content were those obtained with a ChCL:LA 1:2 molar ratio in DMAC and butanol/HCl assays (25.4 and $2447 \mathrm{mg}$ epicatechin/100 $\mathrm{g}$ of sample, respectively). However, results using a butanol/HCl assay exhibited no significant differences $(p>0.05)$ with 1:3 ChCL:LA and 1:3 ChCl:EG. 
Table 3. Total PA content (DMAC and butanol/HCl assays) and total antioxidant capacity (ABTS and capacity to inhibit the formation of hydroxyl radical assays) obtained from the extraction residue of mangosteen peel using UAE, with ChCl:LA and ChCl:EG at different molar ratios (1:1, 1:2, and 1:3).

\begin{tabular}{|c|c|c|c|c|}
\hline NaDES & $\begin{array}{c}\text { DMAC (mg Epicatechin/100 g } \\
\text { Sample) }\end{array}$ & $\begin{array}{c}\text { Butanol/HCl (mg } \\
\text { Epicatechin/100 g Sample) }\end{array}$ & $\begin{array}{l}\text { Hydroxyl Radical } \\
\text { (\% of Inhibition) }\end{array}$ & $\begin{array}{c}\% \text { Scavenging of } \\
\text { ABTS Radicals }\end{array}$ \\
\hline \multicolumn{5}{|l|}{ ChCl:LA } \\
\hline $1: 1$ & $13.7 \pm 0.5^{\mathrm{d}}$ & $1230 \pm 182^{b}$ & $33 \pm 5^{a, b}$ & $13.9 \pm 0.8^{\mathrm{d}}$ \\
\hline $1: 2$ & $25.4 \pm 0.6^{\mathrm{a}}$ & $2447 \pm 237^{a}$ & $24 \pm 5^{b}$ & $34 \pm 2^{c}$ \\
\hline $1: 3$ & $18.7 \pm 0.6^{b}$ & $2277 \pm 386^{\mathrm{a}}$ & $24 \pm 4^{b}$ & $15 \pm 1^{\mathrm{d}}$ \\
\hline \multicolumn{5}{|l|}{ ChCl:EG } \\
\hline $1: 2$ & $9.2 \pm 0.9^{\mathrm{e}}$ & $623 \pm 110^{c}$ & $39 \pm 8^{a}$ & $65 \pm 4^{\mathrm{a}}$ \\
\hline $1: 3$ & $16.9 \pm 0.5^{c}$ & $2187 \pm 436^{\mathrm{a}}$ & $31 \pm 3^{a}$ & $39 \pm 1^{b}$ \\
\hline
\end{tabular}

Note: ${ }^{a, b, c, d, e}$ Different superscript letters indicate the significant differences $(p \leq 0.05)$.

To sum up, the extracts obtained with ChCl:EG (1:2 and 1:3 molar ratios) had higher antioxidant capacity than those corresponding to ChCl:LA (1:2 and 1:3 molar ratios) (Table 3). Moreover, the extracts obtained with ChCl:LA (1:2) presented the highest total PA content. Therefore, ChCl:LA with a 1:2 molar ratio, which exhibited the highest PA content and a high total antioxidant capacity, was chosen to perform the optimization of NEP extraction from the extraction residue of mangosteen peel (Table 3).

\subsection{Optimization of the NaDES-UAE Extraction Parameters for NEPs from Mangosteen Peel Extraction Residue}

Once the NaDES (ChCl:LA) and the molar ratio between components (1:2) were selected to release NEPs from the extraction residue of mangosteen peel, a Box-Behnken experimental design was employed to optimize the percentage of water, the ultrasound amplitude, and the extraction time on five response variables for evaluating the total PA content (DMAC and butanol/ $\mathrm{HCl}$ assays) and total antioxidant capacities (capacity to inhibit the formation of hydroxyl radicals, capacity to scavenge free radicals, and ferricreducing antioxidant power (FRAP) methods). The values explored for these variables were set up based on the information found in the literature as well as the instrumentation and sample limitations. For instance, to reduce solvent viscosity, water was added in a range from 10 to $30 \%(v / v)$ due to higher water concentrations that might have restricted the interactions between NaDES and phenolic compounds by affecting hydrogen-bonded interactions $[57,58]$. As can be seen in Table S1, by experimental design, the established 15 experiments were conducted in a randomized order, with three replicated at the central point. In addition, Table S1 presents the total PA content and total antioxidant capacity of the extracts attained in the 15 experiments.

Table S2 compiles the results of the adequacy of the model as well as the analysis of variance, goodness of fit, and the coefficients of the established multiple linear regression. The regression models enabled prediction of $93.6-99.3 \%$ of the variability of the results obtained by DMAC, butanol $/ \mathrm{HCl}$, ABTS scavenging capacity, capacity to inhibit the formation of hydroxyl radical, and FRAP assays. These values indicated that the applied model was suitable. Furthermore, ANOVA was used to determine the competence of the regression model and the results (see Table S2). Most of the responses presented $p$-values for the lack-of-fit test that were higher than 0.05 , being adequate, except for the ABTS scavenging capacity assay ( $p$-value $=0.0082$ ) showing the suitable fitting of data to the model (see Table S2). The effects of the variables on the responses are shown as a response surface 3-D contour plot (Figure 2). According to Figure 2A,B and data grouped in Table S2, the extraction time and ultrasound amplitude were positively correlated with the extraction of PAs. In addition, the percentage of water presented a negative correlation with the total PA content measured by butanol $/ \mathrm{HCl}$ assay, while it did not have a significant influence $(p>0.05)$ with the DMAC assay. On the other hand, the total antioxidant capacity of the extracts was also positively correlated with the extraction time and the ultrasound 
amplitude, whereas the percentage of water displayed a negative correlation when the antioxidant capacity was measured by the capacity to inhibit the formation of hydroxyl radicals and the capacity to scavenge $\mathrm{ABTS}^{\bullet+}$ assays, being also negative but not significant the influence of water percentage on the antioxidant capacity displayed by FRAP assay (Figure 2C-E).
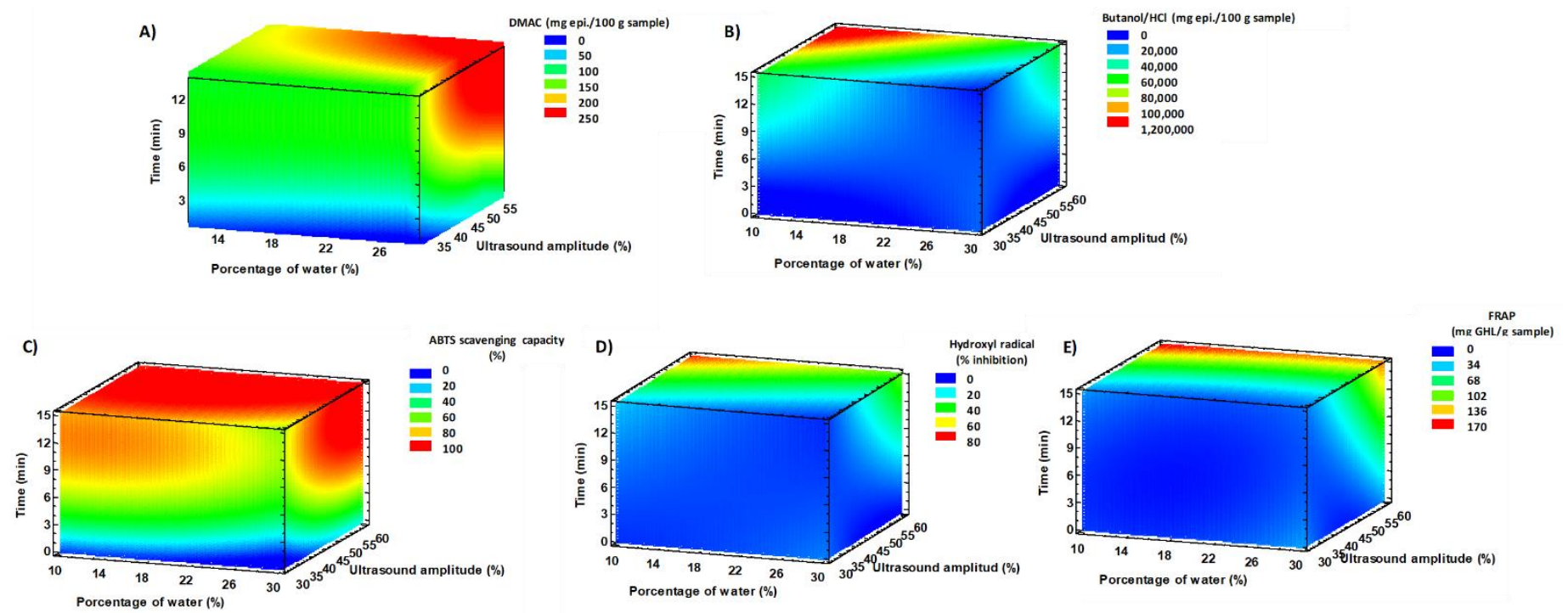

Figure 2. 3-D contour plots showing the effects of the extraction time ( $\mathrm{min})$, the ultrasound amplitude (\%), and the percentage of water (\%) in the NaDES (ChCl:LA, 1:2) on the total PA content (DMAC (A) and butanol/ $\mathrm{HCl}(\mathbf{B})$ assays) and total antioxidant capacity (ABTS scavenging capacity $(\mathbf{C})$, capacity to inhibit the formation of hydroxyl radicals (D), and FRAP (E) assays) of extracts obtained from the extraction residue of mangosteen peel.

As shown in Table 4, the optimal extraction conditions to release PAs with high antioxidant capacity were a percentage of water of $18.8 \%(v / v)$, employing an ultrasound amplitude of $60 \%$ for $15 \mathrm{~min}$. Table 4 displays the theoretical optimal values that should be reached under optimal UAE-NaDES conditions and the experimental results obtained under these conditions by following the methodology described in Section 2.4. The experimental values of total PA content, using the DMAC method, and antioxidant capacity, measured by the capacity to scavenge $\mathrm{ABTS}^{\bullet+}$ and inhibit the formation of hydroxyl radicals, were within the theoretical values of the predictive model. However, the experimental values obtained regarding the total PA content exhibited by the butanol/ $\mathrm{HCl}$ assay as well as the total antioxidant capacity showed with the FRAP assay were lower and higher, respectively, than the theoretical values (see Table 4). In general, the results obtained through confirmation experiments indicated that the predictive model from the experimental design predicted well the extraction of antioxidant NEPs by UAE, with ChCl:LA (1:2) as the solvent, from the extraction residue of mangosteen peel. 
Table 4. Optimal extraction conditions (percentage of water, ultrasound amplitude, and extraction time) to release antioxidant NEPs from the extraction residues of mangosteen peels by UAE with ChCl:LA (1:2). Theoretical and experimental values of total PA content (DMAC and butanol/ $\mathrm{HCl}$ assays) and total antioxidant capacity (scavenging capacity of ABTS radicals, capacity to inhibit the formation of hydroxyl radicals, and FRAP methods) obtained under optimal UAE conditions as well as the results on the extraction of EEPs using a conventional extraction method.

\begin{tabular}{|c|c|c|c|}
\hline & $\begin{array}{c}\text { Water Percentage } \\
(\%)\end{array}$ & $\begin{array}{c}\text { Ultrasound } \\
\text { Amplitude (\%) }\end{array}$ & $\begin{array}{c}\text { Extraction Time } \\
\text { (min) }\end{array}$ \\
\hline UAE optimal extraction conditions & 18.8 & 60.0 & 15.0 \\
\hline Response Variables & $\begin{array}{c}\text { UAE Theoretical } \\
\text { Values }\end{array}$ & $\begin{array}{c}\text { UAE Experimental } \\
\text { Values }\end{array}$ & $\begin{array}{l}\text { Conventional } \\
\text { Extraction }\end{array}$ \\
\hline DMAC (mg epicatechin/100 g sample) & 219.95 & $238 \pm 21$ & $2.4 \pm 0.2$ \\
\hline Butanol/HCl (mg epicatechin/100 g sample) & 102,200 & $37,638 \pm 6389$ & $1017 \pm 57$ \\
\hline Scavenging capacity of ABTS radicals (\%) & 105.57 & $113 \pm 10$ & $14 \pm 1$ \\
\hline Hydroxyl radicals (\% of hydroxyl radical inhibition) & 61.14 & $66 \pm 9$ & $5.0 \pm 0.4$ \\
\hline FRAP (mg GSH/g sample) & 153.28 & $283 \pm 17$ & $1.58 \pm 0.08$ \\
\hline
\end{tabular}

3.4. Comparison of NEP Extraction by UAE-NaDES from the Extraction Residue of Mangosteen Peel with the Conventional Extraction of EPPs from Mangosteen Peel

As can be observed in Table 4, the extracts collected from the extraction residue of mangosteen peel, using the optimal UAE-NaDES extraction conditions to reach the highest content of antioxidant NEPs, were compared with the extracts obtained by the conventional extraction method of antioxidant EPPs from mangosteen peel. The optimal UAE-NaDES extraction method obtained extracts with higher PA contents and total antioxidant capacities than the extracts obtained by the conventional extraction method. These results highlighted that after conventional extraction, many antioxidant phenolic compounds were still retained in the extraction matrix, which were underestimated when the extractable polyphenols were extracted.

Moreover, the molecular weight distribution of NEPs and EPPs recovered by optimal UAE-NaDES and conventional extraction methods from mangosteen peels, respectively, were estimated by HPLC-SEC to learn the molecular weight of the released phenolic compounds [44]. Figure 3A,B displays both chromatograms at the same concentration (50 mg sample/mL), obtained for the extracts of NEPs and EPPs, respectively. The molecular weight distribution of the NEP extracts showed that the optimal UAE-NaDES method released phenolic compounds with high (6900-7500 Da), medium (2000-3000 Da), and low $(<100 \mathrm{Da})$ molecular weights (Figure $3 \mathrm{~A})$. However, the extracts obtained by the conventional extraction method showed two chromatographic peaks, one of high molecular weight $(7100 \mathrm{Da})$ and the other of low molecular weight $(<100 \mathrm{Da})$ (Figure 3B). The extracts obtained by conventional extraction from mangosteen peel displayed higher amounts of the compounds of $<100 \mathrm{Da}$, while the optimal extraction method, based in UAE with $\mathrm{ChCl}$ :LA (1:2), allowed the release of NEPs with higher molecular weights. 


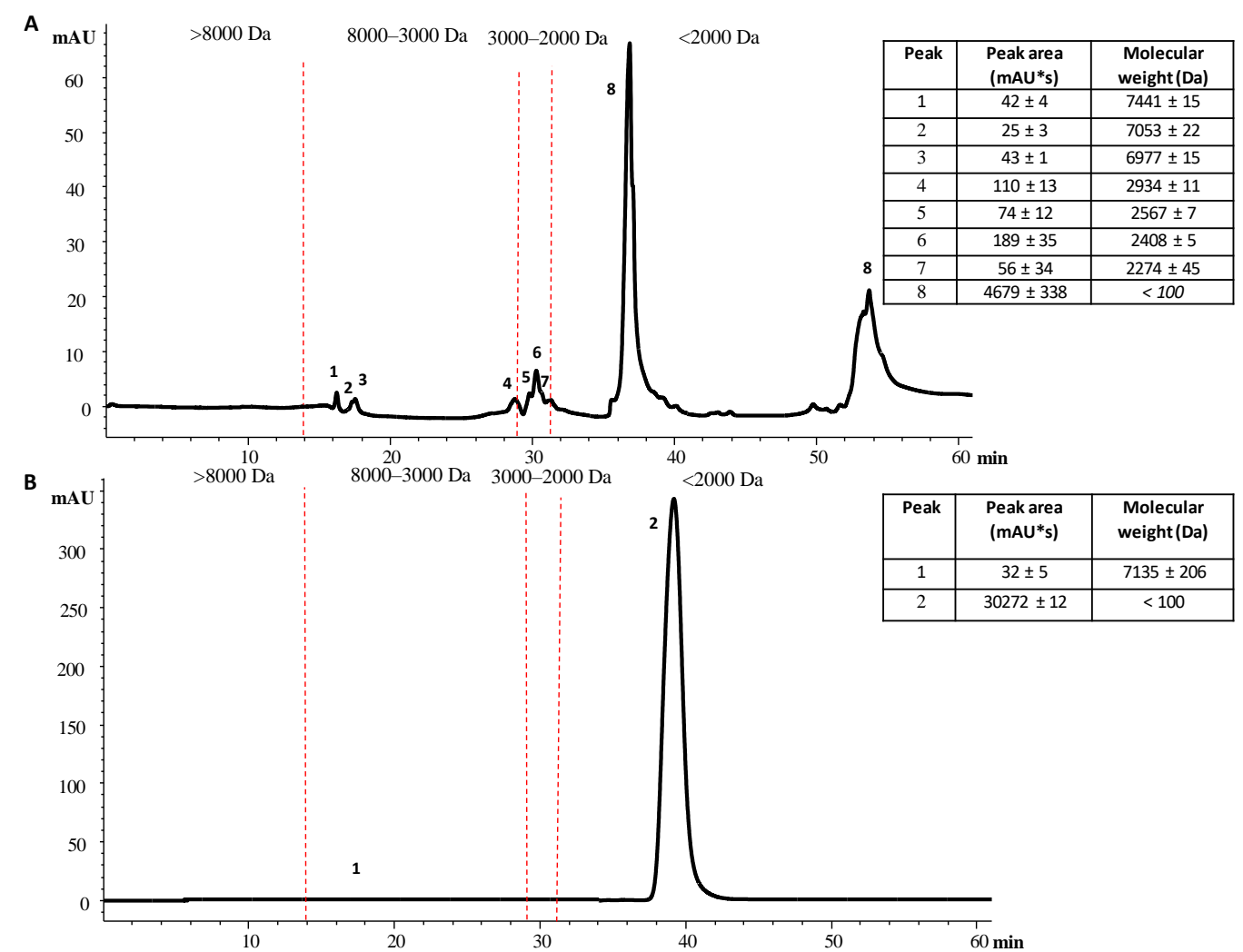

Figure 3. HPLC-SEC chromatogram profiles of the NEP extracts obtained under the optimal extraction conditions (60\% ultrasound amplitude, $18.8 \%$ water percentage, and 15 min extraction time) by UAE with ChCl:LA (1:2) as the extraction solvent (A) and EPP extracts collected after conventional extraction methods (B) from mangosteen peel.

On the other hand, the phenolic profiles of the extracts obtained by the optimal UAE-NaDES and conventional extraction methods were also analyzed by reverse-phase HPLC-DAD. Figure 4 shows the chromatograms obtained at the same concentration (50 mg sample/mL), which demonstrate that many phenolic compounds were retained in the extraction residue after the conventional extraction of mangosteen peel. The DAD spectra analysis of the separated compounds allowed the classification of phenolic compounds by family groups. For instance, the selected wavelengths of 280, 360, and $510 \mathrm{~nm}$ made possible the identification of phenolic compounds, flavonols and xanthones, and anthocyanins, respectively [59]. Six anthocyanins, 4 flavonols, 7 xanthones, and 8 phenolic compounds (phenolic acids) were found in the extracts of NEPs (Figure 4A). The extract obtained by conventional extraction methods presented 4 xanthones (Figure $4 \mathrm{~B}$ ). Therefore, the comparison of both extracts at the same concentration revealed that the developed extraction method to release NEPs from the extraction residue of mangosteen was more efficient for extracting phenolic compounds than the conventional extraction method for recovering EPPs from mangosteen peel. 


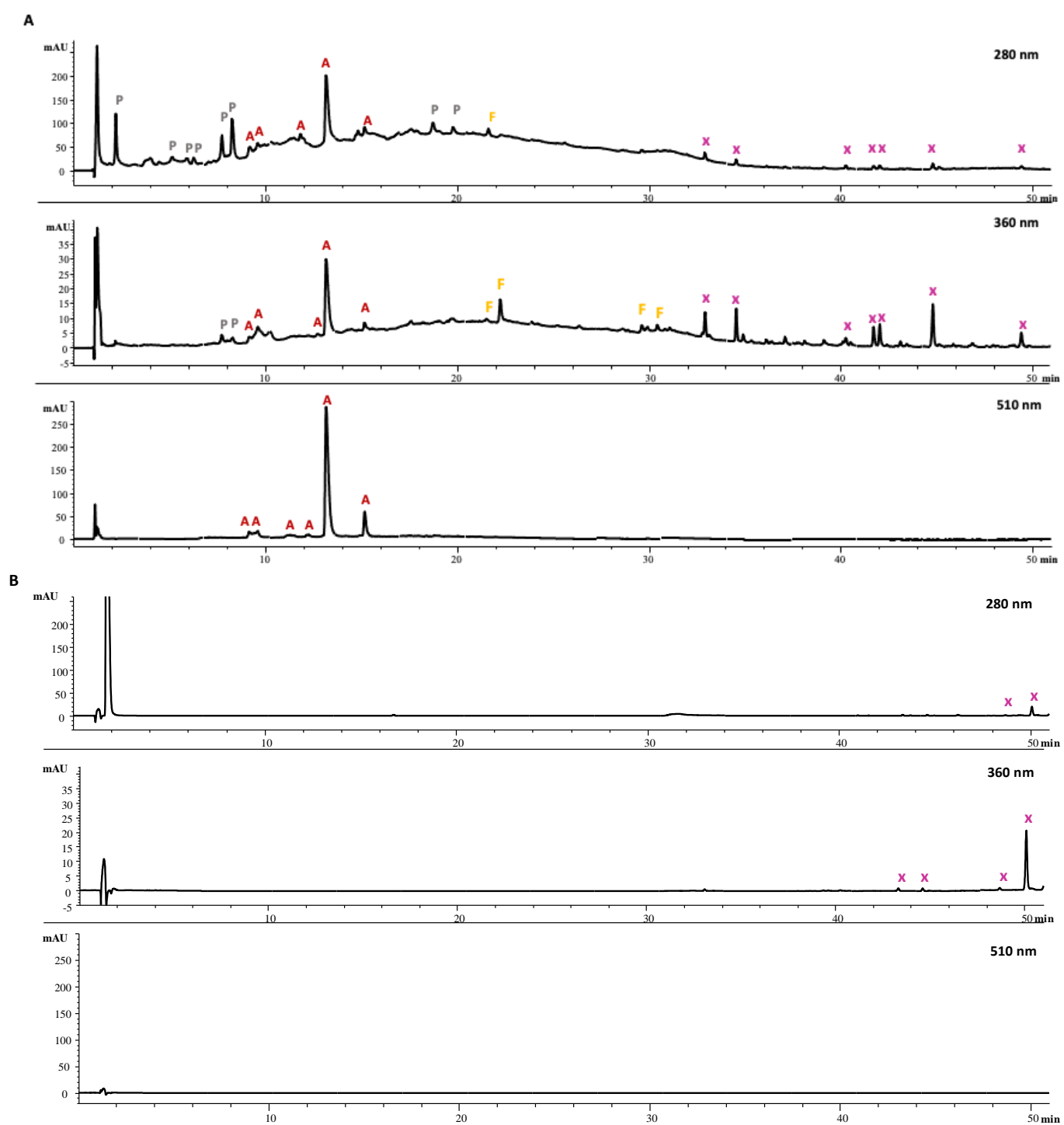

Figure 4. HPLC-DAD chromatograms at 280, 360, and $510 \mathrm{~nm}$ corresponding to the analyses of the NEPs and EPPS of extracts obtained by the optimal UAE-NaDES (ChCl:LA, 1:2) method (60\% ultrasound amplitude, $18.8 \%$ water percentage, and 15 min extraction time) (A) and the conventional extraction method (B), respectively, from mangosteen peel. P: phenolic compound; X: xanthones; F: flavonols; and A: anthocyanins.

\subsection{Effect of NEP Extracts Obtained by UAE with ChCl:LA from the Extraction Residue of Mangosteen Peel on Viability in HeLa Cells}

Another aspect to be considered is the cytotoxicity assessment of NEPs extracted from mangosteen peel as well as the extraction solvent employed (ChCl:LA (1:2)), which is scarcely reported in the literature. NaDES are considered sustainable solvents with low toxicity because they are composed of safe ingredients. However, the combination of these ingredients with low toxicity might present synergistic toxic effects when the eutectic mixture is formed [60]. Figure 5 shows the cytotoxic capacity of the NEP extracts obtained under optimal UAE conditions, with ChCl:LA as the extraction solvent, from the extraction residue of mangosteen peel at four different concentrations $(0.025-0.500 \mathrm{mg} / \mathrm{mL})$ (Figure 5), as well as the cytotoxic capacity of the employed extraction solvent, creating the same dilutions as for the extracts with milli-Q water (Figure 5) on HeLa cell cultures. From 0.025 to $0.500 \mathrm{mg} / \mathrm{mL}$ extract, cell viability was slightly modified but without significant differences among $0.025,0.050$, and $0.250 \mathrm{mg} / \mathrm{mL}$ extract, displaying low cytotoxicity of the extracts (reduction of cell viability around $20 \%$ ). 


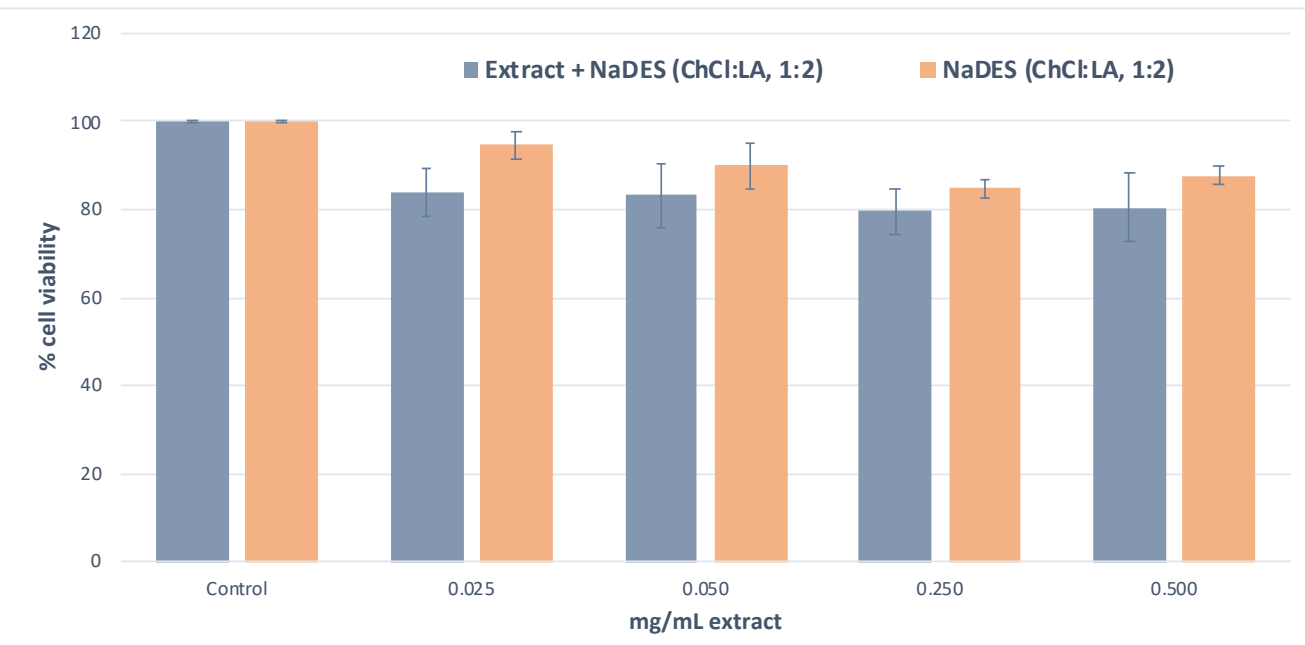

Figure 5. Effects of the extracts diluted with milli-Q water at four different concentrations $(0.025-0.500 \mathrm{mg} / \mathrm{mL})$, obtained under optimal extraction conditions (60\% ultrasound amplitude, $18.8 \%$ water percentage, and 15 min extraction time) by $\mathrm{UAE}$, with ChCl:LA (1:2) as the extraction solvent, from the extraction residue of mangosteen peel (blue color), as well as the effects of NaDES diluted with the same amount of milli-Q-water as the extracts (orange color) on cell viability in HeLA cells.

\section{Conclusions}

This work presents, for the first time, an efficient and sustainable extraction method based on the use of NaDES, in combination with UAE, for NEPs' release from the extraction residue of mangosteen peel. After the screening process, solvents such as ChCl:LA (1:2) and ChCl:EG (1:2) were selected due to their high PA contents and antioxidant capacities. In addition, the molar ratios of the components acting as HBAs and HBDs in the NaDES were studied, and ChCl:LA with a 1:2 molar ratio was chosen because this NaDES created extracts with higher antioxidant and PA contents. The use of the Box-Behnken experimental design allowed the investigation of the influence of the percentage of water in the extraction solvent, the ultrasound amplitude, and the extraction time upon the release of NEPs from the matrix. The optimal extraction conditions to recover NEPs by UAE, with ChCl:LA (1:2) as the extraction solvent, were a percentage of water of $18.8 \%(v / v)$, an ultrasound amplitude of $60 \%$, and 15 min extraction time. This method was suitable to extract NEPs with high antioxidant capacity from the extraction residue of mangosteen peel, presenting extracts with a higher PA content, antioxidant capacity, and number of phenolic compounds than the extracts of EEPs obtained from mangosteen peel through the conventional extraction method. Moreover, the optimized extraction method enabled the recovery of phenolic compounds with higher molecular weights than the conventional extraction method. Therefore, the developed green method seems to be a promising tool for the extraction of antioxidant NEPs from mangosteen peels.

Supplementary Materials: The following are available online at https: / www.mdpi.com/article/ 10.3390/app11125625/s1, Table S1: Experimental design obtained by Box-Behnken and total PA content (DMAC and butanol/HCl assays) and antioxidant capacity (FRAP assays and hydroxyl assays, scavenging capacity of ABTS radicals, and capacity to inhibit the formation of hydroxyl radical assays) of the extracts obtained under the established conditions for the extraction of NEPs from mangosteen peel using UAE with ChCl:LA (1:2); Table S2: Coefficients of the multiple linear regression models obtained for UAE with ChCl:LA (1:2) that best fitted the responses (total PA content (DMAC and butanol/ $\mathrm{HCl}$ assays) and antioxidant capacity (FRAP assays and hydroxyl assays, scavenging capacity of ABTS radicals, and capacity to inhibit the formation of hydroxyl radical assays)) with extraction parameters A: water percentage; B: ultrasound amplitude; and C: time) as well as analysis of variance (ANOVA).

Author Contributions: Conceptualization, M.P. and M.L.M.; Methodology, M.P. and M.L.M.; Validation, M.P. and C.S.; Formal analysis, M.P. and G.D.-R.; Investigation, C.S. and G.D.-R.; Resources, 
M.P. and M.L.M.; Data curation, C.S. and G.D.-R.; Writing-original draft preparation, M.P., G.D.-R. and C.S.; Writing-review and editing, M.P. and M.L.M.; Visualization, M.P., C.S. and G.D.-R.; Supervision, M.P. and M.L.M.; Project administration, M.P. and M.L.M.; Funding acquisition, M.P. and M.L.M. All authors have read and agreed to the published version of the manuscript.

Funding: Authors thank the financial support from the Comunidad of Madrid (Spain) and European funding from the FSE and FEDER Programs (project S2018/BAA-4393, AVANSECAL-II-CM) and the Comunidad of Madrid and the University of Alcalá for research project CM/JIN/2019-033 (SOSBIO).

Acknowledgments: G.D.-R. thanks the University of Alcalá for her predoctoral FPI contract.

Conflicts of Interest: The authors declare no conflict of interest.

\section{References}

1. Baiano, A. Recovery of biomolecules from food wastes: A review. Molecules 2014, 19, 14821-14842. [CrossRef] [PubMed]

2. Rico, X.; Gullón, B.; Alonso, J.L.; Yáñez, R. Recovery of high value-added compounds from pineapple, melon, watermelon and pumpkin processing by-products: An overview. Food Res. Int. 2020, 132, 109086. [CrossRef]

3. Esparza, I.; Jiménez-Moreno, N.; Bimbela, F.; Ancín-Azpilicueta, C.; Gandía, L.M. Fruit and vegetable waste management: Conventional and emerging approaches. J. Environ. Manag. 2020, 265, 110510. [CrossRef] [PubMed]

4. Jung, H.A.; Su, B.N.; Keller, W.J.; Mehta, R.G.; Kinghorn, D. Antioxidant Xanthones from pericarp of Garcinia mangostana (Mangosteen). J. Agric. Food. Chem. 2006, 54, 2077-2082. [CrossRef] [PubMed]

5. Suttirak, W.; Manurakchinakorn, S. In vitro antioxidant properties of mangosteen peel extract. J. Food Sci. Technol. 2012, 51, 1-13. [CrossRef]

6. Zadernowski, R.; Czaplicki, S.; Naczk, M. Phenolic acid profiles of mangosteen fruits (Garcinia mangostana). Food Chem. 2009, 112, 685-689. [CrossRef]

7. Pothitirat, W.; Chomnawang, M.T.; Supabphol, R.; Gritsanapan, W. Comparison of bioactive compounds content, free radical scavenging and anti-acne inducing bacteria activities of extracts from the mangosteen fruit rind at two stages of maturity. Fitoterapia 2009, 80, 442-447. [CrossRef] [PubMed]

8. Pedraza-Chaverri, J.; Cárdenas-Rodríguez, N.; Orozco-Ibarra, M.; Pérez-Rojas, J.M. Medicinal properties of mangosteen (Garcinia mangostana). Food Chem. Toxicol. 2008, 46, 3227-3239. [CrossRef]

9. Kusmayadi, A.; Adriani, L.; Abun, A.; Muchtaridi, M.; Tanuwiria, U.H. The effect of solvents and extraction time on total xanthone and antioxidant yields of mangosteen peel (Garcinia mangostana L.) extract. Drug Invent. Today 2018, 10, 2572-2576.

10. Saputri, F.A.; Mayangsari, A.; Muchtaridi, M. The optimization of eluting condition of solid phase extraction method for ï-mangostin purification in mangosteen pericarp extract. Int. J. Appl. Pharm 2018, 10, 112-114.

11. Bundeesomchok, K.; Filly, A.; Rakotomanomana, N.; Panichayupakaranant, P.; Chemat, F. Extraction of $\alpha$-mangostin from Garcinia mangostana L. using alternative solvents: Computational predictive and experimental studies. LWT Food Sci. Technol. 2016, 65, 297-303. [CrossRef]

12. Pérez-Jiménez, J.; Díaz-Rubio, M.E.; Saura-Calixto, F. Non-extractable polyphenols in plant foods: Nature, isolation, and analysis. In Polyphenols in Plants; Academic Press: Cambridge, MA, USA, 2014; pp. 203-218.

13. Acosta-Estrada, B.A.; Gutiérrez-Uribe, J.A.; Serna-Saldívar, S.O. Bound phenolics in foods, a review. Food Chem. 2014, 152, 46-55. [CrossRef]

14. Han, Y.; Huang, M.; Li, L.; Cai, X.; Gao, Z.; Li, F.; Xiao, H. Non-extractable polyphenols from cranberries: Potential antiinflammation and anti-colon-cancer agents. Food Funct. 2019, 10, 7714-7723. [CrossRef] [PubMed]

15. Domínguez-Rodríguez, G.; Marina, M.L.; Plaza, M. Strategies for the extraction and analysis of non-extractable polyphenols from plants. J. Chromatogr. A 2017, 1514, 1-15. [CrossRef]

16. Turner, C. Sustainable analytical chemistry-more than just being green. Pure Appl. Chem. 2013, 85, 2217-2229. [CrossRef]

17. Gullón, P.; Gullón, B.; Romaní, A.; Rocchetti, G.; Lorenzo, J.M. Smart advanced solvents for bioactive compounds recovery from agri-food by-products: A review. Trends Food Sci. Technol. 2020, 101, 182-197. [CrossRef]

18. Fernández, M.A.; Espino, M.; Gómez, F.J.V.; Silva, M.F. Novel approaches mediated by tailor-made Green solvents for the extraction of phenolic compounds from agro-food industrial by-products. Food Chem. 2018, 239, 671-678. [CrossRef] [PubMed]

19. Koutsoukos, S.; Tsiaka, T.; Tzani, A.; Zoumpoulakis, P.; Detsi, A. Choline chloride and tartaric acid, a Natural Deep Eutectic Solvent for the efficient extraction of phenolic and carotenoid compounds. J. Clean. Prod. 2019, 241, 118384. [CrossRef]

20. Dai, Y.; Verpoorte, R.; Choi, Y.H. Natural deep eutectic solvents providing enhanced stability of natural colorants from safflower (Carthamus tinctorius). Food Chem. 2014, 159, 116-121. [CrossRef]

21. Bentley, J.; Olsen, E.K.; Moore, J.P.; Farrant, J.M. The phenolic profile extracted from the desiccation-tolerant medicinal shrub Myrothamnus flabellifolia using Natural Deep Eutectic Solvents varies according to the solvation conditions. Phytochemistry 2020, 173, 112323. [CrossRef] [PubMed]

22. Chanioti, S.; Katsouli, M.; Tzia, C. Novel Processes for the Extraction of Phenolic Compounds from Olive Pomace and Their Protection by Encapsulation. Molecules 2021, 26, 1781. [CrossRef] [PubMed] 
23. Bosiljkov, T.; Dujmic, F.; Bubalo, M.C.; Hribar, J.; Vidrih, R.; Brncic, M.; Zlatic, E.; Redovnikovic, I.R.; Jokic, S. Natural deep eutectic solvents and ultrasound-assisted extraction: Green approaches for extraction of wine lees anthocyanins. Food Bioprod. Process. 2017, 102, 195-203. [CrossRef]

24. Ameer, K.; Shahbaz, H.M.; Kwon, J.H. Green extraction methods for polyphenols from plant matrices and their byproducts: A review. Compr. Rev. Food Sci. Food Saf. 2017, 16, 295-315. [CrossRef]

25. Alanon, M.E.; Ivanovic, M.; Gómez-Caravaca, A.M.; Arraéz-Román, D.; Segura-Carretero, A. Choline chloride derivative-based deep eutectic liquids as novel green alternative solvents for extraction of phenolic compounds from olive leaf. Arab. J. Chem. 2020, 13, 1685-1701. [CrossRef]

26. Saratale, G.D.; Saratale, R.G.; Varjani, S.; Cho, S.K.; Chodake, G.S.; Kadam, A.; Mullar, S.I.; Bharagava, R.N.; Kim, D.S.; Shin, H.S. Development of ultrasound aided chemical pretreatment methods to enrich saccharification of wheat waste biomass for polyhydroxybutyrate production and its characterization. Ind. Crops Prod. 2020, 150, 112425. [CrossRef]

27. Paiva, A.; Craveiro, R.; Aroso, I.; Martins, M.; Reis, R.L.; Duarte, A.R.C. Natural Deep eutectic solvents-Solvents for the 21s century. ACS Sustain. Chem. Eng. 2014, 2, 1063-1071. [CrossRef]

28. Hernández-Corroto, E.; Plaza, M.; Marina, M.L.; García, M.C. Sustainable extraction of proteins and bioactive substances from pomegranate peel (Punica granatum L.) using pressurized liquids and deep eutectic solvents. Innov. Food Sci. Emerg. Technol. 2020, 60, 102314. [CrossRef]

29. Barbieri, J.B.; Goltz, C.; Cavalheiro, F.B.; Toci, A.T.; Igarashi-Mafra, L.; Mafra, M.R. Deep eutectic solvents applied in the extraction and stabilization of rosemary (Rosmarinus officinalis L.) phenolic compounds. Ind. Crops Prod. 2020, 144, 112049. [CrossRef]

30. Gullón, B.; Muñiz-Mouro, A.; Lú-Chau, T.A.; Moreira, M.T.; Lema, J.M.; Eibes, G. Green approaches for the extraction of antioxidants from eucalyptus leaves. Ind. Crops Prod. 2019, 138, 111473. [CrossRef]

31. Pal, C.B.T.; Jadeja, G.C. Microwave-assisted deep eutectic solvent extraction of phenolic antioxidants from onion (Allium cepa L.) peel: A Box-Behnken design approach for optimization. J. Food Sci. Technol. 2019, 56, 4211-4223. [CrossRef]

32. Duan, L.; Zhang, W.H.; Zhang, Z.H.; Liu, E.H.; Guo, L. Evaluation of natural deep eutectic solvents for the extraction of bioactive flavone C-glycosides from FlosTrollii. Microchem. J. 2019, 145, 180-186. [CrossRef]

33. Tan, Y.T.; Ngoh, G.C.; Chua, A.S.M. Effect of functional groups in acid constituent of deep eutectic solvent for extraction of reactive lignin. Bioresour. Technol. 2019, 281, 359-366. [CrossRef]

34. Zhou, H.C.; Lin, Y.M.; Wei, S.D.; Tam, N.F.Y. Structural diversity and antioxidant activity of condensed tannins fractionated from mangosteen pericarp. Food Chem. 2011, 129, 1710-1720. [CrossRef]

35. Condezo-Hoyos, L.; Mohanty, I.P.; Noratto, G.D. Assessing non-digestible compounds in applecultivars and their potential as modulators of obese faecal microbiota in vitro. Food Chem. 2014, 161, 208-215. [CrossRef]

36. Zurita, J.; Díaz-Rubio, M.E.; Saura-Calixto, F. Improved procedure to determine non-extractable polymeric proanthocyanidins in plant foods. Int. J. Food Sci. Nutr. 2012, 63, 936-939. [CrossRef]

37. Taha, F.S.; Wagdy, S.M.; Singer, F.A. Comparison between antioxidant activities of phenolic extracts from different parts of peanut. Life Sci. 2012, 99, 207-215.

38. Montero, L.; Herrero, M.; Ibáñez, E.; Cifuentes, A. Profiling of phenolic compounds from different apple varieties using comprehensive two-dimensional liquid chromatography. J. Chromatogr. A 2013, 1313, 275-283. [CrossRef] [PubMed]

39. Pérez-Jiménez, J.; Arranz, S.; Saura-Calixto, F. Proanthocyanidin content in foods is largely underestimated in the literature data: An approach to quantification of the missing proanthocyanidins. Food Res. Int. 2009, 42, 1381-1388. [CrossRef]

40. Re, R.; Pellegrini, N.; Proteggente, A.; Pannala, A.; Yang, M.; Rice-Evans, C. Antioxidant activity applying an improved ABTS radical cation decolorization assay. Free Radic. Biol. Med. 1999, 26, 1231-1237. [CrossRef]

41. Hernández -Corroto, E.; Marina, M.L.; García, M.C. Multiple protective effect of peptides released from Olea europaea and Prunus persica seeds against oxidative damage and cancer cell proliferation. Food Res. Int. 2018, 106, 458-467. [CrossRef] [PubMed]

42. Ajibola, C.F.; Fashakin, J.B.; Fagbemi, T.N.; Aluko, R.E. Effect of peptide size on antioxidant properties of African yam bean seed (Sphenostylis stenocarpa) protein hydrolysate fractions. Int. J. Mol. Sci. 2011, 12, 6685-6702. [CrossRef]

43. Hasanuzzaman, M.; Nahar, K.; Anee, T.I.; Fujita, M. Glutathione in plants: Biosynthesis and physiological role in environmental stress tolerance. Physiol. Mol. Biol. Plants 2017, 23, 249-268. [CrossRef]

44. Domínguez-Rodríguez, G.; Marina, M.L.; Plaza, M. Enzyme-assisted extraction of bioactive non-extractable polyphenols from sweet cherry (Prunus avium L.) pomace. Food Chem. 2021, 339, 128086. [CrossRef]

45. Domínguez-Rodríguez, G.; García, M.C.; Plaza, M.; Marina, M.L. Revalorization of Passiflora species peels as a sustainable source of antioxidant phenolic compounds. Sci. Total Environ. 2019, 696, 134030. [CrossRef]

46. Choi, Y.H.; Verpoorte, R. Green solvents for the extraction of bioactive compounds from natural products using ionic liquids and deep eutectic solvents. Curr. Opin. Food Sci. 2019, 26, 87-93. [CrossRef]

47. Žlabur, J.Š.; Voća, S.; Brnč, M.; Rimac-Brnč, S. New Trends in Food Technology for Green Recovery of Bioactive Compounds From Plant Materials. In Role of Materials Science in Food Bioengineering; Academic Press: Cambridge, MA, USA, 2018 ; pp. 1-36.

48. Alanon, M.E.; Ivanovic, M.; Pimentel-Mora, S.; Borrás-Linares, I.; Arraez-Roman, D.; Segura-Carretero, A. A novel sustainable approach for the extraction of value-added compounds from Hibiscus sabdariffa L. calyces by natural deep eutectic solvents. Food Res. Int. 2020, 137, 109646. [CrossRef] [PubMed]

49. Ivanocic, M.; Alanon, M.E.; Arráerz-Román, D.; Segura-Carretero, A. Enhanced and green extraction of bioactive compounds from Lippia citriadora by tailor-made natural deep eutectic solvents. Food Res. Int. 2018, 111, 67-76. [CrossRef] 
50. Loarce, L.; Oliver-Simancas, R.; Marchante, L.; Díaz-Maroto, M.C.; Alanon, M.E. Implementation of subcritical water extraction with natural deep eutectic solvents for sustainable extraction from winemaking by-products. Food Res. Int. 2020, 137, 109728. [CrossRef]

51. Wang, Y.; Singh, A.P.; Hurst, W.J.; Glinski, J.A.; Koo, H.; Vorsa, N. Influence of degree-of-polymerization and linkage on the quantification of proanthocyanidins using 4-dimethylaminocinnamaldehyde (DMAC) assay. J. Agric. Food Chem. 2016, 64, 2190-2199. [CrossRef]

52. Shay, P.E.; Trofymow, J.A.; Constabel, C.P. An improved butanol-HCl assay for quantification of water-soluble, acetone: Methanolsoluble, and insoluble proanthocyanidins (condensed tannins). Plant Methods 2017, 13, 63. [CrossRef] [PubMed]

53. Ong, S.Y.; Wain, A.; Groombridge, L.; Grimes, E. Forensic identification of urine using the DMAC test: A method validation study. Sci. Justice 2012, 52, 90-95. [CrossRef] [PubMed]

54. Radošević, K.; Ćurko, N.; Gaurina Srček, V.; Bubalo, M.; Tomašević, M.; Kovačević Ganić, K.; Radojčić Redovniković, I. Natural deep eutectic solvents as beneficial extractants for enhancement of plant extracts bioactivity. LWT Food Sci. Technol. 2016, 73, 45-51. [CrossRef]

55. Kalpna, R.; Mital, K. Vegetable and fruit peels as a novel source of antioxidants. J. Med. Plants Res. 2011, 5, 63-71.

56. Gangwar, M.; Gautam, M.K.; Sharma, A.K.; Tripathi, Y.B.; Goel, R.K.; Nath, G. Antioxidant capacity and radical scavenging effect of polyphenol rich Mallotus philippinensis fruit extract on human erythrocytes: An in vitro study. Sci. World J. 2014, $2014,279451$. [CrossRef] [PubMed]

57. El Kantar, S.; Rajha, H.N.; Boussetta, N.; Vorobiev, E.; Maroun, R.G.; Louka, N. Green extraction of polyphenols from grapefruit peels using high voltage electrical discharges, deep eutectic solvents, and aqueous glycerol. Food Chem. 2019, 295, 165-171. [CrossRef]

58. Garcia, A.; Rodriguez-Juan, E.; Rodriguez-Gutierrez, G.; Rios, J.J.; Fernandez-Bolanos, J. Extraction of phenolic compounds from virgin olive oil by deep eutectic solvents (DESs). Food Chem. 2016, 197, 554-561. [CrossRef]

59. Lorrain, B.; Pechamat, L.; Teissedre, P.L. Evolution of analysis of polyphenols from grapes, wines, and extracts. Molecules 2013, 18, 1076-1100. [CrossRef]

60. Hayyan, M.; Hashim, M.A.; Hayyan, A.; Al-Saadi, M.A.; AlNashef, I.M.; Mirghani, M.E.E.; Saheed, O.K. Are deep eutectic solvents benign or toxic? Chemosphere 2013, 90, 2193-2195. [CrossRef] 